\title{
Scenarios of Multimedia Presentation of Material Cultural Heritage
}

\author{
Zdenek Vondra ${ }^{1 *}$ \\ ${ }^{1}$ Graphics and Multimedia Laboratory, Faculty of Informatics and Statistics, University of Economics, Prague, CZECH REPUBLIC \\ *Corresponding Author: zdenek.vondra@vse.cz
}

Citation: Vondra, Z. (2018). Scenarios of Multimedia Presentation of Material Cultural Heritage. Mediterranean Journal of Social $\mathcal{E}$ Behavioral Research, 2(2-3), 19-22. https://doi.org/10.30935/mjosbr/8383

\begin{abstract}
This work is the part of research which has aim to define methodology of using multimedia for communication of information content of cultural heritage. Methodology would be primarily used by small and medium enterprises or arts managers. In this paper we ask the question, what multimedia are best to use in certain situations, which lead us to understand the space between them. In this work we base on analysis of communication process, which tells us about the essential elements (initiator, recipient and contents). Main actors of this communication are owners, managers or curators. In the text we are presenting the categories of material cultural heritage, which represent the objects of communication. As the recipients we defined three possible target groups and their motivations to receive this kind of communication based on their expectations. The motivations are professional interest, education and relaxation. According to the cognitive theory of multimedia learning we studied and compared the parameters and connections of multimedia design and made possible scenarios how to create multimedia outputs including photography, graphics, video, animation and sound for presentation of material cultural heritage.
\end{abstract}

Keywords: cultural heritage, communication, information content, multimedia

Received: 22 Apr. 2018 • Accepted: 7 Aug. 2018

\section{INTRODUCTION}

This paper is the part of development of the Methodology to multimedia presentation of cultural heritage for small and medium enterprises. This methodology will be part of superior methodology of managing cultural heritage, which will be certified by Ministry of culture of Czech Republic. Methodology is the output of five years long research made within project NAKI - Effective methodology of supporting small and medium-sized enterprises in the cultural sector in environment of national and European economies. Project is realized by the thematic axis Environment for development of art and preservation of cultural heritage.

This paper presents the concept of reaching goals (presentation needs) by multimedia communication and design in managing material cultural heritage. Initiation to this is happening in specific situations that are defined by communication needs of manager, the contents of communication and target groups including their motivations to receive such information. Within the interconnection of these factors arises the bounded set of usage scenarios of specific kinds of multimedia presentations.

\section{COMMUNICATION OF MATERIAL CULTURAL HERITAGE}

By the study of different approaches to communication we are able to define essential elements of the communication process. These elements are initiator, recipient, message, medium and external influences. By the initiator of communication, we mean the owner, manager or curator of cultural heritage. He is the one who has the need of communicating information of cultural heritage to the society. Motivation for this is caused by his participation in arts management activities, cultural development, tourism or research (especially historical). It is demanded by curators, restoration and interpretation activities or by the processes of animation of cultural heritage. Initiator implements a communication by him or by hiring a professional service due to needed skills for making multimedia content. In case of using professional service, there appears the new element in the communication process which is the intermediary of communication. Recipient of communication is basically the target group, which is segmented by its motivations for receiving the information from cultural heritage. Contents of communication or the message is bound to the existence of cultural heritage. It is the result of combining communication needs of initiator and motivations of recipient. In case 
of European context, the recipient dominates the market, so in case of designing the communication it is necessary to primarily answer to their motivations. In this paper medium of communication presents multimedia output situated in communication space. The external influences summarize all other factors that affect communication from outside of the process.

Goal of the communication respectively of the presentation of material cultural heritage is primarily inform about their existence, form, qualitative aspects, mechanics and context. Context simplifies the factual information and connections to the intangible cultural heritage. Fulfilling of communication goals of initiator is connected to the motivation and selection made by target groups. Mission for presentation of cultural heritage is not only to tell the information, but also to be visible for selected target groups so they can find the information.

The matters of communication are objects that have the typology defined by the documents of UNESCO. These documents are also the patterns for the laws of cooperating countries. Categories of material cultural heritage for the purposes of this work:

- Architectural works

- Sculptures

- Paintings

- The cave dwellings

- The combination of elements

- Groups of buildings

- Sites

- Items

Categories of material cultural heritage written in documents of UNESCO are for the purpose of multimedia presentation slightly modified. UNESCO mentions apart the list above one another category, which is inscriptions. By the point of view of our methodology, they can be classified as the sculptures (if they are depicted in space) or the paintings (if they are depicted in surface). Category items was added beyond the UNESCO documents and means the items of daily use.

The way of presentation of cultural heritage is according to the goals defined by its manager. These goals arise from his social and economic motivations and head to appropriate target groups. Cultural heritage can participate in society by many modes, from scientific causes, that emphasizes the interpretation of facts, and then to the many levels of educational and leisure time activities, which are mostly connected with animation of cultural heritage.

For the purpose of study possibilities of multimedia presentation to different target groups there was established the criteria knowledge. If we consider the seven principles of multimedia learning, so it is just the seventh principle of special effects (Mayer, 2009), which define a general target group between experts and laymen according to selected criteria. By the principle of special effects we can directly argue for ratio of special effects (meaning audiovisual emphasis, beautification) and of pure information according to knowledge of target group.

Motivation for experts to receive information about cultural heritage can be defined on the base of research as follows (Amin, van Ossenbruggen, Hardman van, \& Nispen, 2008):

- Comparison

- Relationship search

- Topic search
- Exploration

- Combination

Experts choose the information actively by themselves for their future use. They give the accent to clarity, brevity, factual and verifiable significance. From the view of communication, they prefer clear interpretation without any additions. Layman's attitude is defined by the study of tourism, so their key motivations are recreation and relaxation. Their demands for information are the opposite of experts, so they do not need clear interpretation but rather the experience. In extreme cases received information should not be on cultural heritage monument, they are visiting or meeting. In the imaginary space between experts and layman oscillates target group which's motivation is education. It can take many forms based on the ratio of personal experience and the search for facts thus animation and interpretation of cultural heritage.

\section{MULTIMEDIA AND DEVELOPMENT OF SCENARIOS}

Multimedia has the place in process of communication as the specific type of media. Their principles are based on connection of imaginary and narrative content, which brings synergic multiple effect of delivering the message to its recipient (Paivio, 1986). By narration we mean verbal content (text or speech). By images we mean the capture or representation of real world by nonverbal form usually by picture. Most common forms of multimedia are based on the combination of text, graphics, photography, animation, video, sound and interaction through the application procedures (Vaughan, 2008).

On this basis, we can define the essential variations of tools combinations for creating multimedia outputs.

Variants according to static tools (electronic or printed brochure or publication):

- Text

- Text + Photography

- Text + Graphics

- Text + Photography + Graphics

Variants according to dynamic linear tools (reproduced by electronic appliance):

- Text + Sound

- Text + Video + Sound

- Text + Animation + Sound

- Text + Video + Animation + Sound

Variants according to dynamic non-linear tools (only in electronic environment):

- Application or website + Text

- Application or website + Text + Graphics

- Application or website + Text + Photography

- Application or website + Text + Photography + Graphics

- ... + Sound

- ... + Video + Sound

- ... + Animation + Sound

- ... + Video + Animation + Sound 
Table 1. Variant forms of multimedia tools content

\begin{tabular}{lll}
\hline & Capture of reality & Experience \\
\hline Text & Facts description & Literary work \\
\hline Photography & Capture of reality & Art photography \\
\hline Graphics & Technical drawing & Illustration \\
\hline Animation & Dynamic technical drawing & Animated illustration \\
\hline Video & Dynamic capture of reality, reconstruction of events & Film \\
\hline Sound & Spoken comment, historical sound records & Music, sound effects, atmosphere \\
\hline Application or website & Contents organized to hypertext & Application (educative, game) \\
\hline
\end{tabular}

Listed variant combinations of tools represent overview of possible technical scenarios, for now without reflection communication need of initiator and motivation of target group. Cognitive theory of multimedia learning explains that combination of narrations and images ensure the more intensive transmission of message.

At this point, it is useful to describe the basic motivations of initiator for involvement the cultural property in society:

- Communicate information about cultural property

- Provide for professional purposes

- Educate

- Animation of cultural heritage

- Activities related to the cultural property

- Activities non-related to the cultural property

- Attract, presentation, advertising

- Inform about the existence of a cultural property and related activities to enable the fulfillment of the abovementioned points

From the list above it is partly clear, which variations of tools will be appropriate to meet those goals. Static tools variants are appropriate to selection and active perception of recipient. This corresponds to state, that they are principally suitable for informing. Their ability of attraction is limited by lower intensity of effect on perception. Recipient is relatively free to select contents to receive. Dynamic linear tools variants are more intense on perception. Their combination of medial layers screened in time in row has synergy effect of the picturing techniques. Recipient has low possibility of selection and then his perception is passive. Therefore, these tools are suitable for attraction and for intensive communication, when are not desirable perception activity of recipient. However, their limit is a need of electronic appliance to show the communication. Dynamic non-linear tools variants are basically combination of previous two groups, where their elements are organized into the complex. There recipient's perception is more or less selective in accordance to setup of multimedia variants. Depending on their configuration they oscillate between attraction and clear information. Their use is possible only in digital environment, which means, that they also need electronic appliances for work.

In relation to motivation of target groups, multimedia uses two main parameters, which are informational and emotional representation. Let remind the principle of special effects from cognitive theory of multimedia learning. That is describing how to create multimedia in accordance to knowledge and then also the motivation of target groups. Informational representation has goal to communicate facts. Emotional representation is made by adding esthetical elements to make communication more attractive or more expressive than the real world. This kind of representation brings more intensive experience from perception to recipient but also has the side effect of losing factual information. However in all cases of representation inclusive informational, it is necessary to abide certain level of esthetic quality. It is connected with culture and cognitive skills of target groups to ensure that they will take the message and understand. Too low level of esthetic quality can cause effect of loose attention to message because of deeper attention focused on esthetic mistakes.

Table 1 describes variant forms of multimedia tools content, that reflect motivations of target groups and also motivations of initiator for communication. For accurate targeting of communications contents it is used additional levels that are means of expression of individual multimedia tools. Every means of expression allow enrichment of real picture or drawing by emotional content addition. By this, the message of media is regulated. Means of expression are for the purpose of this paper divided to three groups according to common elements:

Visual text processing, graphics and animation

- Color model

- Arrangement

- Vector content

- Raster content (including post-production)

- Typography

- Print techniques

- (In the case of animation we use some parameters also used in video)

Photography a video

- Exposure

- Coloring

- Composition

- Depth of field

- Movement, shutter speed

- Post-production

Sound

- Dynamics

- Frequency range

- Effects

- Mix (musical expression, voice resources, noise, atmosphere, ambient)

\section{DISCUSSION}

The resulting set of scenarios of using multimedia for presentation of material cultural heritage is based on tool combination variants, on variant forms of content and on level of emotional enrichment of means of expression of multimedia. Based on these findings and lists showed 
in the text the manager of material cultural heritage is able to define his communication need and find appropriate target group. He is able to create or demand communication for attraction, animate or inform about cultural heritage. For this purpose there is defined the space between peripheral cases (expertise and relaxation) and parameters of variants between them. For realizing of technical aspects manager will study only the selected tools procedures.

In case of small and medium sized enterprises there is the restrictive factor the financial resources. Lack of money would discard the optimal variant of communication because of high costs. In this case it is appropriate to find in this designed concept the alternative that will be also suitable and won't have such high costs. Mostly it will be changing the dynamic linear media to dynamic non-linear or static or change settings of means of expression. Another challenge for development of the Methodology to multimedia presentation of cultural heritage for small and medium enterprises is to handle the problem of communication of intangible cultural heritage, which cannot be depicted in its own existence, but only in connection with human activities or material cultural heritage.

\section{REFERENCES}

Amin, A., van Ossenbruggen J., Hardman, L., \& van Nispen, A. (2008) Understanding cultural heritage experts' information seeking needs. In Proceedings of the 8th ACM/IEEE-CS (pp. 39-47). New York: ACM. https://doi.org/10.1145/1378889.1378897

Biocca, F. A. (1988). Opposing conceptions of the audience: The active and passive hemispheres of mass communication theory. Communication yearbook 11 (pp. 51-80). University of North Carolina, Chapel Hill. https://doi.org/10.1080/23808985.1988. 11678679
Byrnes, W. J. (2009). Management and the arts (4th ed.) Boston: Elsevier Focal Press.

Communication Theory (2010). Berlo's SMCR model of communication. Retrieved from http://communicationtheory.org/berlos-smcrmodel-of-communication/

Horny, S. (2013). Úvod do multimédir. Prague: Oeconomica.

Lasswell, H. (1971). The Structure and function of communication in society In Schramm, W. \& Roberts, D. F. (Ed.) The Process and Effects of Mass Communication (pp. 84-99). Urbana: University of Illinois Press.

Mayer, R. E. (2009). Multimedia learning (2nd ed.). Cambridge: Cambridge University Press. https://doi.org/10.1017/ CBO9780511811678

Paivio, A. (1986). Mental representations: a dual coding approach. Oxford: Oxford University Press.

Pechová, Z. (2011). Metody animace kulturně-historického dédictví (Doctoral dissertation). Retrieved from Information system of Masaryk university, Brno http://is.muni.cz/th/66118/pedf_d/

Richards, G. (1996). Cultural tourism in Europe. Wallingford, UK: CAB International.

UNESCO. (1972). Convention Concerning the Protection of the World Cultural and Natural Heritage. Retrieved from http://whc.unesco.org/en/conventiontext/

Vaughan, T. (2008). Multimedia: making it work (7th ed.). New York: McGraw-Hill. 